\title{
Case 154: New Circumareolar Suture
}

\author{
Michael J. Higgs, Ron P. Bezic, and John Walker
}

\subsection{Submitted by Higgs: December 7, 2012}

For some time I have been performing mastopexy and reduction using a CV-3 Gore-Tex suture as a circumareolar purse string.

Recently, this suture has been impossible to procure in Australia so I asked my friends at Dynek (a local suture assembler) for a solution. Since then, I have used a 3-0 yellow monofilament nonabsorbable Radene (polyvinylidene fluoride
PVDF) on a straight cutting needle for the purse string. This has proven easier to use and is less elastic than the Gore-Tex, which I think is a good thing in preventing scar stretching.

Figure 109.1 shows the Radene in use.

\section{Bezic}

Thanks for the info, Michael (Higgs). I will definitely get a box.

\section{Walker: December 8, 2012}

Can they send us some?

\section{Higgs}

Dear John (Walker) and Group,

Go to www.dynek.com and 'contact us'. Email address is dynek@dynek.com.

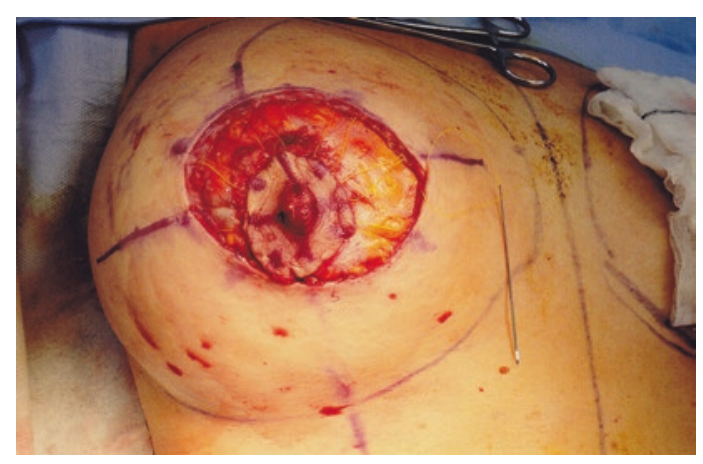

Fig. 109.1 Circumareolar Radene suture

M.J. Higgs, M.B. B.S. ( $₫)$

Parkside Cosmetic Surgery,

7 Unley Road, Parkside, Adelaide, SA 5063,

Australia

e-mail:drmike@parksidecosmetic.com.au

R.P. Bezic, M.B. B.S.

Cosmedical Clinic,

31 Grosvenor St., Woollahra 2025, Australia

Wollongong Cosmetic Clinic,

74/200 Crown St., Wollongong 2500, Australia

e-mail: bezic@tpg.com.au

J. Walker, M.D.

Private Practice, 330 Temple Ave, Long Beach,

CA 90814, Australia

e-mail: john_walker777@yahoo.com 